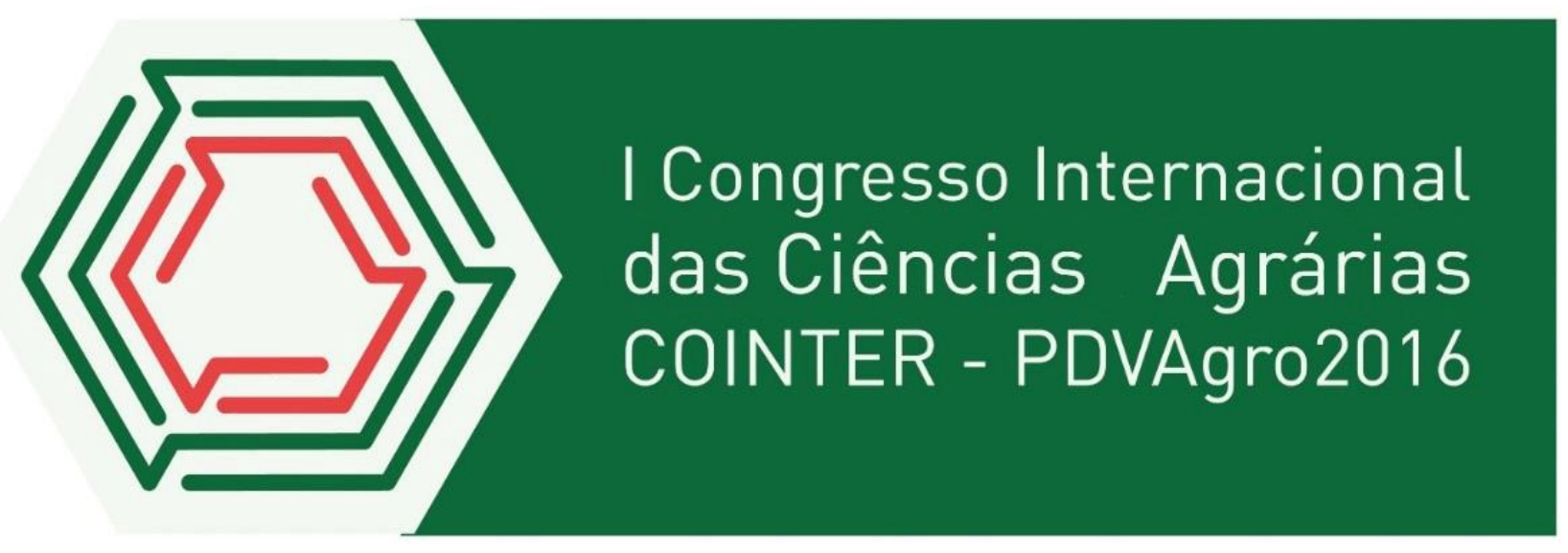

\title{
IMPLANTAÇÃO DE JARDIM DESÉRTICO
}

Apresentação: Relato de Experiência

Maria da Guia de Medeiros ${ }^{1}$; Josefa Edinaja Chaves da Silva² ${ }^{2}$ Erikson Kadoshe de Morais Raimundo $^{3}$; Jussara Hellen Morais Frazão ${ }^{4}$

\section{Introdução}

A falta de água é um grande problema enfrentado nas cidades localizadas no semiárido, pois possuem um baixo índice pluviométrico. Logo, as plantas mais adequadas para o paisagismo nessas localidades são as cactáceas e suculentas, visto que não necessitam de água regularmente devido seu mecanismo de armazenamento (CARNEIRO, 2004).

\section{Relato de Experiência}

Foi o primeiro jardim desértico temático (representa a caatinga) implantado no Centro de Ciências Humanas, Sociais e Agrárias, em que boa parte das plantas utilizadas foram produzidas no viveiro do próprio centro e as demais foram adquiridas em uma comunidade rural.

Um planejamento foi feito para determinar onde cada planta seria fixada, organizando-as de forma em que as plantas da mesma espécie ficassem agrupadas, utilizando o espaçamento de $15 \mathrm{~cm}$ entre plantas da mesma espécie e $30 \mathrm{~cm}$ de espécies diferentes.

A areia branca foi utilizada para revestir o solo e facilitar a drenagem da água, devido às plantas que foram utilizadas não podem ficar encharcadas, pois pode provocar apodrecimento das raízes. A areia colorida (esverdeada), foi utilizada fazendo contornos orgânicos para dar um destaque em algumas espécies.

\footnotetext{
${ }^{1}$ Bacharelado em Agroecologia, UFPB, dagmedeirospb@gmail.com

2 Licenciatura em Ciências Agrarias, UFPB, edinaja2013@gmail.com

${ }^{3}$ Bacharelado em Agroecologia, UFPB, kadoshetecagro@hotmail.com

${ }^{4}$ Pra Dra , UFPB, jmoraisfrazao@yahoo.com.br
} 
As espécies utilizadas foram: Palma brava: Opuntia microdasys (Cactácea); Dyckia brevifolia (Bromélia); Cacto-candelabro: Euphorbia ingens (Cactácea); X Pachyveria (Suculenta); Huernia macrocarpa (Suculenta); Kalanchoe marnieriana (Suculenta); Crassula argentea (Suculenta); Opuntia cochenillifera (Cactácea); Melocactus bahiensis (Cactácea); Schumbergera russeliana (Cactácea)

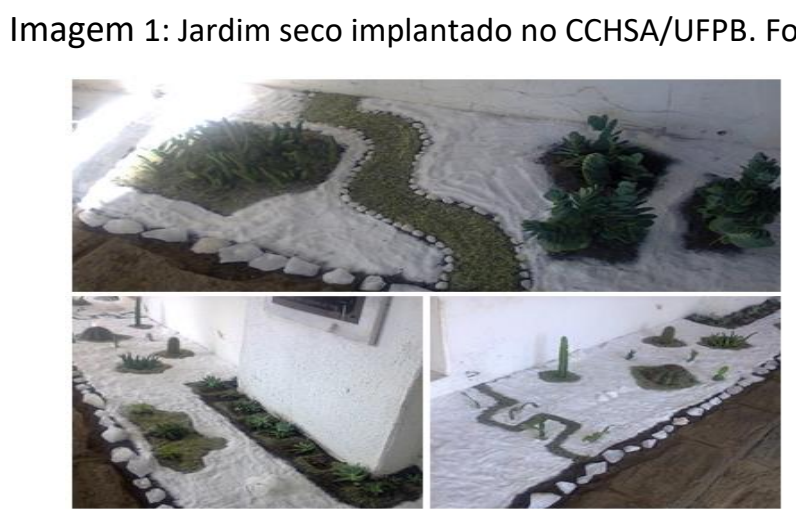

A possibilidade de se criar jardins que requisitem menos tratos, e, principalmente, que permita a combinação de novos elementos proporcionará ume feito estético novo que exigirá um empenho do paisagista em conhecer como a planta se comporta em seu ambiente natural e de que forma e local ela poderá ser implantada. (ALVAREZ \& KIILL, 2014).

No entanto, no semiárido, poucas são as cidades que utilizam espécies originárias da caatinga. De acordo com um levantamento feito por Oliveira, et al. (2007) apenas 11\% das plantas utilizadas no paisagismo no centro de Petrolina são plantas da caatinga.

\section{Considerações}

Considerando que a implantação do jardim desértico no Centro de Ciências Humanas, Sociais e Agrárias, foi realizada de uma forma satisfatória, conclui-se que, o mesmo é ideal para lugares onde o índice pluviométrico seja baixo, ou as pessoas não tenham muito tempo de fazer sua manutenção, visto que as plantas reservam águas por períodos de estiagem.

Mesmo sendo um estilo de jardim de importância relevante, principalmente para a região semiárida, não há quase material disponível na literatura sobre esse estilo de jardim.

\section{Referências}


Alvarez, I. A., Kiill, L. H. P. Arborização, Floricultura e Paisagismo com Plantas da Caatinga. Informativo abrates. vo1.24, $\mathrm{n}^{\circ} .3,2014$

CARNEIRO, Maria Isabel Mota et al. ROTEIRO PARA PAISAGISMO NO SEMI-ÊRIDO NORDESTINO. 2004.

OLIVEIRA, Y.M. do N.; PARANHOS, L.G.; ALVAREZ, I.A. Levantamento qualitativo de espécies nos espaços verdes urbanos do centro de Petrolina, PE. In: JORNADA DE INICIAÇÃO CIENTíFICA DA EMBRAPA SEMIÁRIDO, 2,., 2007 (Embrapa Semiárido. Documento, 205). http:// www.alice.cnptia.embrapa.br/bitstream/doc/160386/1 IOPB 1598.pd 